\title{
Percepção de adultos jovens acerca do envelhecimento
}

\author{
Perception of young adults about aging \\ Percepción del envejecimiento de los adultos jóvenes
}

Recebido: 01/12/2021 | Revisado: 05/12/2021 | Aceito: 13/12/2021 | Publicado: 21/12/2021

\author{
Josefa Wanilla da Costa Medeiros \\ ORCID: https://orcid.org/0000-0003-2549-5399 \\ Centro Universitário de João Pessoa, Brasi \\ E-mail: wanilla_medeiros10@hotmail.com \\ Kay Francis Leal Vieira \\ ORCID: https://orcid.org/0000-0002-5440-011X \\ Centro Universitário de João Pessoa, Brasil \\ E-mail: kayvieira@yahoo.com.br \\ Maria Denise Leite Ferreira \\ ORCID: https://orcid.org/0000-0001-8156-3443 \\ Faculdades Nova Esperança, Brasil \\ E-mail: denisecaiana@yahoo.com.br \\ Adriana Lira Rufino de Lucena \\ ORCID: https://orcid.org/0000-0002-3236-4605 \\ Faculdades Nova Esperança, Brasil \\ E-mail: adriana.lira.rufino@hotmail.com
}

\begin{abstract}
Resumo
Entende-se o envelhecimento como sendo parte do processo natural do desenvolvimento humano, que traz consigo mudanças tanto físicas quanto psíquicas, em alguma parcela. Além de biológico, inerente e inevitável, é também um fato culturalmente construído, podendo o meio em que se vive influenciar a percepção das pessoas de determinada sociedade e cultura. Diante disso, objetivou-se identificar a percepção de adultos jovens sobre o processo de envelhecimento, tendo como objetivos específicos caracterizar a amostra em relação ao perfil sociodemográfico; investigar a aceitação do próprio envelhecimento, bem como o conhecimento e posicionamento da amostra em relação aos direitos da pessoa idosa. Trata-se de uma pesquisa de campo, descritiva, de cunho quantitativo, realizada de maneira online com uma amostra de 240 participantes. Utilizou-se um questionário semiestruturado, cujos resultados foram processados através do software SPSS. Foram respeitados todos os preceitos éticos da Resolução 466/12. A maior parte da amostra afirmou perceber o envelhecimento como uma etapa positiva da vida e não ter receio em envelhecer, bem como conhecer e estar de acordo com as Políticas Públicas voltadas para os idosos. Desta forma, percebe-se uma mudança na visão negativa e estereotipada que historiciamente a sociedade vem apresentando em relação as pessoas idosas, dando-se lugar a uma compreensão mais positiva e natural da velhice.
\end{abstract}

Palavras-chave: Envelhecimento; Jovens; Percepção.

\begin{abstract}
Plants with medicinal purposes are part of the great biodiversity, and are introduced in the life of the population since the most Aging is understood to be part of the natural process of human development, which brings changes both physically and psychically. In addition to being biological, inherent and inevitable, it is also culturally constructed, and the environment in which you live can influence the perception of people in a certain society and culture. Therefore, the objective was to identify the perception of young adults about the aging process, and as specific objectives to characterize the sample in relation to the sociodemographic profile; investigating the acceptance of aging itself, as well as the knowledge and positioning of the sample in relation to the rights of the elderly. It is field research, descriptive, quantitative, and carried out online with a sample of 240 participants. As a tool, a semi-structured questionnaire was used, and the results were processed using the SPSS. This study followed all the ethical guidelines of the Resolution 466/12. Most participants perceived aging as a positive stage of life. They were not afraid of getting old. Also, they were prone to know and agree with the Public Policies of the elderly. $\mathrm{n}$ this way, there is a change in the negative and stereotyped view that society has historically presented in relation to the elderly, giving rise to a more positive and natural understanding of old age.
\end{abstract}

Keywords: Aging; Young; Perception.

\section{Resumen}

El envejecimiento se entiende como parte del proceso natural del desarrollo humano, que trae consigo cambios tanto físicos como psicológicos, en alguna parte. Además de ser biológico, inherente e inevitable, también es un hecho construido culturalmente, y el entorno en el que uno vive puede influir en la percepción que tienen las personas de una 
determinada sociedad y cultura. Por tanto, el objetivo fue identificar la percepción de los adultos jóvenes sobre el proceso de envejecimiento, teniendo como objetivos específicos caracterizar la muestra en relación al perfil sociodemográfico; investigar la aceptación del envejecimiento en sí, así como el conocimiento y posición de la muestra en relación a los derechos de las personas mayores. Se trata de una investigación de campo, descriptiva, de carácter cuantitativo, realizada online con una muestra de 240 participantes. Se utilizó un cuestionario semiestructurado, cuyos resultados se procesaron mediante el software SPSS. Se respetaron todos los preceptos éticos de la Resolución 466/12. La mayoría de la muestra manifestó que percibe el envejecimiento como una etapa positiva de la vida y no teme envejecer, además de conocer y cumplir con las Políticas Públicas dirigidas a las personas mayores. De esta forma, se produce un cambio en la visión negativa y estereotipada que históricamente ha presentado la sociedad en relación a las personas mayores, dando lugar a una comprensión más positiva y natural de la vejez.

Palabras clave: Envejecimiento; Joven; Percepción.

\section{Introdução}

O envelhecimento é definido como um processo natural do desenvolvimento humano, encarado como etapa consecutiva à infância, juventude e vida adulta, que traz mudanças físicas, psíquicas e sociais. "Embora envelhecer não signifique necessariamente adoecer (a menos que exista doença associada), o envelhecimento está associado a um bom nível de saúde" (Miranda et al, 2016, p. 508).

Segundo o Estatuto do Idoso (2017), são consideradas idosas as pessoas com idade igual ou superior a 60 (sessenta) anos. Leis e políticas públicas sociais devem garantir a essa população viver com dignidade, segurança, bem estar e qualidade de vida. O fato de o mundo estar envelhecendo se torna ainda mais preocupante no Brasil, que além de ser um país em desenvolvimento, dispõe da cultura ocidental, que segrega e estigmatiza a pessoa idosa na sociedade.

É notório que a cultura ocidental elege a juventude como protagonista dos aspectos mais positivos da vida, pertencentes principalmente - e quase que unicamente - a idade cronológica. Propaga-se a ideia de que estar na "flor" da juventude refere-se ao auge do viver humano e o que vier em posterioridade a essa etapa será sinônimo da decadência e do cansaço: o último estágio do desenvolvimento humano - a velhice. Takeuti (2012, p.3) cita que "a força das significações imaginárias sociais da juventude se denota no fato de todos se sentirem impelidos a permanecer jovem o mais tempo possível, sob fortes ameaças de estigmas de degradação humana produzida pelo tempo, tanto no corpo, na sexualidade como na inteligência".

A figura do ser jovem, adolescente e cheio de vida é tida como positiva, enquanto que ser idoso passa por uma fronteira que o separa dessas características profícuas. Coletivamente, ideias de inatividade, total dependência e perda de autonomia são compartilhadas e tidas como verdadeiras, inclusive, muitas vezes, pelo próprio idoso. Tomando ciência de tal situação, em conjunto com informações comprovadas estatisticamente pelas novas projeções do IBGE (revisão 2018) de que o número da população de idosos vem se tornando crescente nos últimos anos (e que esse percurso será contínuo e de ritmo mais acelerado), percebe-se quão crítico se torna o fato de que no mundo as sociedades estão adentrando numa fase de envelhecimento em proporções e condições socioeconômicas inseguras e arriscadas.

\section{Envelhecimento: caracterização e contextualização}

Entende-se o envelhecimento como processo natural e inerente a toda e qualquer espécie de ser vivo. O processo de envelhecimento traz consigo algumas mudanças biológicas, emocionais e especialmente as físicas, por serem mais perceptíveis. Porém, há que ressaltar-se que a velhice não implica necessariamente em sinônimo de final de percurso, de vida e/ou de objetivos (haja vista que a morte pode ocorrer em quaisquer das fases do desenvolvimento) e, portanto, a condição cronológica por si só não faz referência ao conceito de velhice; mas lembrar de que existem fatores que podem contribuir ou evitar o surgimento de algumas adversidades é importante.

Simone Beauvoir (1970) apud Rosa (2014) destaca que, para além das mudanças biológicas, estão os fatores 
emocionais, a hereditariedade, a ambiência, o padrão de vida e os efeitos da cultura sobre a velhice. O sistema capitalista, forte influente nos nossos padrões culturais, considera que velho pode e até deve ser descartado, fazendo com que impere o ideal da juventude e da modernidade enquanto modelo social a ser aceito e seguido. Este é um fato que pode facilmente ser identificado no nosso cotidiano.

A autora disserta que "devemos atentar para o fato de que a juventude eterna é a grande promessa da atualidade, o que significa que a idade avançada, quando limita o sujeito em sua autonomia e este passa à condição de dependência, pode levar à estigmatização, e a experiência da velhice passa a ser novamente marcada por estereótipos negativos" (Rosa, 2014, p.26). Em decorrência da influência desse sistema, existe entre as pessoas da cultura ocidental uma dificuldade em se reconhecer como sujeitos "velhos", fato este com o qual corrobora a obra de Del-Masso (2015, p. 20):

A aceitação do envelhecimento humano não é uma das tarefas mais fáceis, uma vez que os indivíduos estão condicionados a acreditarem que só os outros envelhecem e que eles permanecerão eternamente jovens, maduros e mais experientes, mas jamais velhos. O culto ao novo, ao atual, ao moderno, transformou o ato de envelhecer em um martírio e um exílio social forçado, causando temor às pessoas que envelhecem. Esse "suposto martírio" é percebido aos primeiros sinais da passagem do tempo e é importante compreender o envelhecimento como um processo que ocorre naturalmente com os indivíduos ao longo de suas vidas, e que não é um fenômeno que ocorre rápido e isoladamente.

Cabe aqui também enfatizar que segundo o Art. $1^{\circ}$ do Estatuto do Idoso (Lei n 10.741/2003), as pessoas idosas têm assegurados os seus direitos fundamentais (físicos, morais, intelectuais, sociais e espirituais) em condição de liberdade e dignidade. O Estatuto traz ainda o reforço às obrigações da família e do Poder Público quanto aos cuidados com a saúde, alimentação, educação, respeito e convivência (Brasil, 2003).

A relevância do Estatuto do Idoso tem sido cada vez mais propagada pela situação preocupante em que se encontra o país. Segundo apontam os dados do IBGE em sua revisão de 2018, "no ano de 2055, as projeções do IBGE indicam o montante de 34,8 milhões de jovens (0-14 anos) e de 70,3 milhões de idosos (60 anos e mais). O Índice de Envelhecimento (IE) será de 202 idosos para cada 100 jovens. Ou seja, haverá mais do dobro de idosos em relação aos jovens” (IHU, 2018).

Ao falar de envelhecimento humano, há ainda que ser levada em consideração a menção a conceitos como a senescência e a senilidade. Enquanto a primeira faz jus ao processo natural de tornar-se velho - o que implica em mudanças comuns como perda de cabelo, flexibilidade e condicionamento físico, enrugamento da pele, etc. -, a segunda refere-se ao corpo envelhecido que está atrelado a certas patologias, mas que não se definem como aspectos comuns a todos os indivíduos nesta idade.

Assim, cada sujeito envelhece a seu modo, dependendo de variáveis como o sexo, origem, lugar em que se vive, a dimensão familiar, aptidões para a vida e as experiências vivenciadas. A exposição ao estresse ou ao tabagismo, a falta de exercícios ou a nutrição inadequada são outros fatores que contribuem para determinar a qualidade do envelhecimento (CIOSAK et al, 2011).

Ainda conforme Ciosak et al. (2011), a saúde e a qualidade vida (QV) da pessoa idosa - mais que de uma pessoa pertencente a qualquer outro grupo ou faixa etária - está suscetível a modificações advindas de múltiplos fatores, tais quais os físicos, psicológicos, sociais e culturais, de tal forma que avaliar e promover a saúde do idoso significa considerar variáveis de distintos campos do saber, numa atuação interdisciplinar e multidimensional. Apesar de se ter caminhado e progredido em tais questões, na contemporaneidade o que se vive são alguns desencontros entre o aumento da expectativa de vida e as restrições em termos de QV: "Esse é o desafio atual, manter os indivíduos vivendo cada vez mais e de maneira saudável" (Marin \& Panes, 2015, p. 221). 


\section{A compreensão da sociedade e da juventude acerca da velhice}

A velhice, além de biológica, inerente e inevitável, é também um fato culturalmente construído, e o meio em que se vive pode influenciar na organização da percepção dos jovens aos quais nos referimos para estudo. Considerando que compartilhamos da cultura ocidental, em um país em que impera o modelo de produção e consumo capitalista, no qual se valoriza a rapidez e a imagem, a velhice acaba por se transformar em algo não desejável. Outro sim, Horn (2013) aponta que a relação entre os sujeitos também é atingida pelo efeito consequente do modelo capitalista, assegurando que os traços narcísicos que temem a velhice acabam por rejeitá-la a si e aos sujeitos que se conferem como velhos.

Desta forma, reafirmando o que foi mencionado anteriormente em relação ao capitalismo, Cruz e Ferreira (2011, p. 148) reiteram:

Ora, se o velho não produz, perde a capacidade de contribuir para a grande engrenagem, não tendo valor em uma sociedade capitalista. $\mathrm{O}$ ideário capitalista leva a crer que a velhice seja um estado que dá prejuízo à produção, uma vez que nesta fase, por conta do declínio biológico, o corpo perde gradativamente sua capacidade de trabalho [...] A imagem que se cria do velho é feia, pois a perda da beleza, caracterizada como o surgimento de sinais físicos próprios da velhice, é feita sempre em oposição à do jovem-belo.

A respeito das relações intergeracionais, ou seja, a relação que se estabelece entre grupos de indivíduos oriundos de uma idade cronológica distinta, conferindo a ambos uma determinada fase da vida, Boaventura (2012) afirma que, em decorrência das diferenças, podem ocorrer conflitos intergeracionais. Caldas e Thomaz (2010, p.82), trazem ainda considerações em seu estudo, onde estas afirmam que, apesar dos jovens terem contato com os velhos, as relações entre ambos podem ser marcadas pela intolerância, ao que chamam de "chatice do velho" e também pela dificuldade de se relacionar com o diferente.

Horn (2013, p. 19) remete à questão do âmbito familiar enquanto fator que deve ser levado em consideração, entendendo a família como o espaço onde buscamos encontrar os recursos necessários tal como o afeto, para vivenciar as demais etapas da vida de maneira mais saudável e satisfatória, no sentido de que "assim como na fase da infância, a velhice também exige do ambiente familiar cuidado frente a suas alterações físicas e psicológicas".

Segundo Pinheiro e Areosa (2018), muitos idosos não sabem qual a melhor forma lidar com esta fase da vida, uma vez que a mesma se caracteriza por muitas mudanças às quais eles devem se adaptar. Um exemplo é a aposentadoria, "ocasião em que o idoso pode apresentar baixa autoestima, pois sente que passam a acontecer limitações na execução de certas tarefas". Tal fato se justifica devido à atividade laboral se constituir como fator importante para a dinâmica das sensações de utilidade e pertencimento (ou seja, para a própria identidade) e que a maioria das empresas ainda resiste em contratar idosos para funcionários.

Assim, o que se percebe é que apesar de a demografia mundial apontar estatisticamente para uma população preponderantemente idosa, os valores propagados pela cultura ocidental, capitalista e da imagem têm como alvo, sobretudo, a juventude. Fato este que colide e traz controvérsias com a realidade atual a qual vivenciamos. Portanto, é tão fundamental conhecer qual a simbologia que representa para o adulto jovem a figura da pessoa idosa quanto que se avalie o que é, de fato, o "ser velho"; haja vista que existem diferentes culturas e que cada uma delas traz sentidos, valores e princípios que diferem entre si e suas sociedades, implicando num tratamento que se distingue em determinação do local geográfico e da cultura predominante.

Desta forma, esta pesquisa teve enquanto objetivo geral identificar a percepção dos jovens sobre o processo de envelhecimento, e como objetivos específicos caracterizar a amostra em relação ao perfil sociodemográfico; investigar a aceitação do próprio envelhecimento, bem como o conhecimento e posicionamento da amostra em relação aos direitos da pessoa idosa. 


\section{Metodologia}

O presente artigo trata-se de um estudo de campo, descritivo e de abordagem quantitativa. Segundo Marconi e Lakatos (2016), a pesquisa de campo consiste na observação de fatos e fenômenos tal como ocorrem espontaneamente, na coleta de dados a eles referentes e no registro de variáveis que se presume relevantes para analisa-los. Já o estudo descritivo têm como objetivo primordial a descrição das características de determinada população ou fenômeno ou, então, o estabelecimento de relações entre variáveis. A abordagem quantitativa, por sua vez, caracteriza-se pelo uso da quantificação edas técnicas estatísticas, tanto nas modalidades de coleta de informações quanto no tratamento delas.

Participaram da amostra 240 jovens, com idades entre 20 a 40 anos, residentes no estado da Paraíba, selecionados através da técnica de amostragem não probabilística. Os participantes responderam a um questionário elaborado pelas próprias autoras e que foi aplicado de forma online. O instrumento foi composto por duas partes, sendo a primeira destinada aos dados sócio- demográficos e a segunda voltada aos objetivos específicos do estudo. Os resultados obtidos foram processados através do Pacote Software SPSS, sendo respeitados todos os preceitos éticos da Resolução 466 de 2012, que aborda pesquisas científicas elaboradas envolvendo seres humanos.

\section{Resultados}

A amostra foi composta por 240 participantes, cujas características sociodemográficas são apresentadas na tabela a seguir:

Tabela 1 - Perfil sociodemográfico dos participantes $(\mathrm{N}=240)$.

\begin{tabular}{lcc}
\hline VARIÁVEL & $\mathbf{N}$ & $\%$ \\
\hline Sexo & 90 & $37,5 \%$ \\
Masculino & 150 & $62,5 \%$ \\
Feminino & & \\
Faixa Etária & 103 & $42,9 \%$ \\
20 a 25 anos & 49 & $20,4 \%$ \\
25 a 30 anos & 52 & $21,7 \%$ \\
30 a 35 anos & 36 & $15 \%$ \\
35 a 40 anos & & \\
& & \\
Nível de Escolaridade & 3 & $1,3 \%$ \\
Ensino Fundamental & 53 & $22 \%$ \\
Ensino Médio & 184 & $76,7 \%$ \\
Ensino Superior & & \\
& & \\
Local em que reside & 181 & $11,6 \%$ \\
Paraíba & 28 & $1,3 \%$ \\
Pernambuco & 03 & $0.4 \%$ \\
Ceará & 01 & $7,9 \%$ \\
Bahia & 19 & $1,3 \%$ \\
Piauí & 03 & $0.4 \%$ \\
Sergipe & 01 & $1,6 \%$ \\
Rio Grande do Norte & 04 & \\
Maranhão & & \\
\hline
\end{tabular}

Fonte: Dados da pesquisa (2020).

Mediante análise do questionário específico foi possível verificar a percepção que os participantes possuem a respeito do envelhecimento, conforme demonstra a Tabela 2: 
Tabela 2 - Percepção de jovens adultos acerca do envelhecimento ( $\mathrm{N}=240)$.

\begin{tabular}{lcc}
\hline QUESTÕES & $\mathbf{N}$ & $\%$ \\
\hline 1. Para você, o envelhecimento é uma etapa negativa da vida? & 65 & $27,1 \%$ \\
Sim & 175 & $72,9 \%$ \\
Não & & \\
2. Você tem medo de envelhecer? & 90 & $37,5 \%$ \\
Sim & 150 & $62,5 \%$ \\
Não & & $\%$ \\
\hline
\end{tabular}

Fonte: Dados da pesquisa (2020).

A terceira e última tabela traz os resultados obtidos no que tange à percepção dos participantes em relação aos direitos dos idosos:

Tabela 3 - Percepção dos participantes quanto aos direitos dos idosos $(\mathrm{N}=240)$.

\begin{tabular}{|c|c|c|}
\hline QUESTÕES & $\mathbf{N}$ & $\%$ \\
\hline \multicolumn{3}{|c|}{ Você conhece alguma Política Pública voltada para os idosos? } \\
\hline $\operatorname{Sim}$ & 170 & 70,8 \\
\hline Não & 70 & 29,2 \\
\hline \multicolumn{3}{|c|}{$\begin{array}{l}\text { O que você pensa a respeito do direito dos idosos a atendimento com prioridade } \\
\text { em repartições, empresas de serviços públicos e em bancos? }\end{array}$} \\
\hline Discordo totalmente & 2 & 0,8 \\
\hline Discordo & 3 & 1,3 \\
\hline Não concordo nem discordo & 8 & 3,3 \\
\hline Concordo & 25 & 10,4 \\
\hline Concordo totalmente & 202 & 84,2 \\
\hline \multicolumn{3}{|c|}{$\begin{array}{l}\text { O que você pensa a respeito do idoso poder usar gratuitamente o transporte } \\
\text { coletivo urbano? }\end{array}$} \\
\hline Discordo totalmente & 2 & 0,8 \\
\hline Discordo & 1 & 0,4 \\
\hline Não concordo nem discordo & 7 & 2,9 \\
\hline Concordo & 9 & 3,8 \\
\hline Concordo totalmente & 221 & 92,1 \\
\hline \multirow{2}{*}{\multicolumn{3}{|c|}{$\begin{array}{l}\text { O que você pensa a respeito de o idoso poder viajar nos ônibus interestaduais de } \\
\text { graça (Se houver vaga), ou com } 50 \% \text { de desconto? } \\
\text { Discordo totalmente }\end{array}$}} \\
\hline & & \\
\hline Discordo & 3 & 1,3 \\
\hline Não concordo nem discordo & 2 & 0,8 \\
\hline Concordo & 10 & 4,2 \\
\hline Concordo totalmente & 16 & 6,7 \\
\hline \multicolumn{3}{|c|}{$\begin{array}{l}\text { O que você pensa a respeito de o idoso ter direito à vaga prioritária em } \\
\text { estacionamentos tanto públicos quanto privados? } \\
\text { Discordo totalmente }\end{array}$} \\
\hline Discordo & 4 & 1,7 \\
\hline Não concordo nem discordo & 1 & 0,4 \\
\hline Concordo & 6 & 2,5 \\
\hline \multirow[t]{2}{*}{ Concordo totalmente } & 16 & 6,7 \\
\hline & 213 & 88,7 \\
\hline \multicolumn{3}{|c|}{ Em um ônibus lotado, você cederia seu espaço para um idoso sentar-se? } \\
\hline Sim & 232 & $96,7 \%$ \\
\hline Não & 8 & $3,3 \%$ \\
\hline
\end{tabular}

Fonte: Autores. 


\section{Discussão}

De acordo com a Tabela 1, os resultados referentes aos dados sociodemográficos apresentam o predomínio de mulheres (62,5\%), com nível de escolaridade superior (76,7\%), média de idade entre 20 e 25 anos $(42,9 \%)$ e $75 \%$ dos participantes residem no estado da Paraíba.

Conforme os dados apresentados na Tabela 2, à maioria das participantes (72,9\%) afirmou que o envelhecimento não se caracteriza como uma etapa negativa da vida, divergindo da literatura mencionada em parte teórica do presente estudo. Paz et al (2012) certificam que, comumente, em contextos históricos diferentes, atribuem-se poderes para cada ciclo da vida, e que em paralelo existe um "desinvestimento" por parte da política e do social ao idoso. Tal desinvestimento implica, na maioria das culturas, numa tendência à separação, segregação e à morte (real ou simbólica) desses indivíduos. Junto a isto se apresenta o estudo de Veras et al (2015, p.2), que corrobora: "quando se define o envelhecimento e/ou a velhice, percebe-se que o preconceito é uma característica marcante e é utilizado como estereótipo negativo sobre a velhice".

Já no que se refere ao medo de envelhecer, verificou-se que (62,5\%) dos jovens informaram não possuir esse receio, havendo aqui novamente uma discrepância entre os resultados obtidos e a teoria apresentada, ao passo em que Del-Masso (2015) incrementa que existe entre as pessoas da cultura ocidental uma dificuldade em se reconhecer e se aceitarem como sujeitos velhos, pois fomos condicionados a acreditar que somente os outros é que envelhecem, que seremos jovens permanentemente; talvez maduros e com mais experiência, porém jamais velhos. Tal ideia é apoiada pela fala de Schneider e Irigaray $(2008$, p.4) em que sustentam que "ao mesmo tempo em que as pessoas querem viver muito, não querem ficar velhas nem se parecer com velhos".

Destaca-se que ambos os autores supracitados possuem pesquisas realizadas em anos diferentes e relativamente distantes tanto entre si quanto do momento atual em que estamos; o que reafirma que o envelhecimento, em nossa cultura e realidade, não tem sido tomado por uma ótica positiva pela grande maioria há tempos. "Mesmo nos dias atuais, o envelhecimento aparece associado a doenças e perdas, e é na maioria das vezes entendido como apenas um problema médico" (Schneider \& Irigaray, 2008, p.2).

Nesta perspectiva, considerando que grande parte da amostra foi composta por mulheres $(62,5 \%)$, a obra de Torres et al (2015) acrescentam que junto às mudanças que ocorrem no corpo, provocadas pelo envelhecimento e pelo tempo, há ainda a dependência de muitos idosos e as diferenças entre a fase atual e a futura, o que gera a dificuldade e o medo que se tem de envelhecer para as mulheres. Ocorre, então, uma nitidez quanto à disparidade das respostas obtidas e da literatura até aqui respaldada.

A terceira e última tabela traz os resultados obtidos no que tange à percepção dos participantes em relação aos direitos legais dos idosos, declarando que a maior parte dos respondentes $(70,8 \%)$ afirma conhecer as Políticas Públicas voltadas para idosos e estar de acordo com a condição da pessoa idosa a ter prioridade tanto em atendimentos institucionais (84,2\%); vagas de estacionamentos (88,7\%); quanto ao direito à gratuidade no uso do transporte coletivo urbano municipal (92,1\%) e gratuidade (ou desconto de 50\%) em passagens de ônibus interestaduais (87,1\%). Ademais, 96,7\% da amostra afirmou ceder seu espaço para um idoso em um ônibus lotado.

O fato de os participantes estarem cientes da existência de Políticas Públicas para os idosos é de suma relevância social, pois como apontaVeros (2018, p.2) os princípios das políticas públicas norteiam e direcionam para "respostas frente aos desafios do processo de envelhecimento com novos conceitos versando sobre independência, participação, cuidados e dignidade". Assim, as Políticas Públicas estão para a garantia do respeito às pessoas idosas e conferem a prática dessas leis.

A Lei N $\mathrm{N}^{\mathrm{B}}$ 8.842, de 04 de janeiro de 1994 dispõe sobre a Política Nacional do Idoso - PNI (que tem por objetivo assegurar os direitos sociais do idoso, criando condições para promover sua autonomia, integração e participação efetiva na sociedade), cria o Conselho Nacional de Direitos do Idoso - CNDI (que tem como competência elaborar, implementar, 
acompanhar e avaliar a Política Nacional do Idoso, observando as diretrizes presentes na Lei $\mathrm{n}^{\mathrm{o}} 10.741$, de $1^{\mathrm{o}}$ de outubro de 2003 - Estatuto do Idoso) e dá outras providências.

O Estatuto do Idoso (revisão 2017), em sua Lei de n 10.741/2003, Capítulo X - Do Transporte; Art. 40, determina que:

No sistema de transporte coletivo interestadual observar-se-á, nos termos da legislação específica: I - A reserva de 2 (duas) vagas gratuitas por veículo para idosos com renda igual ou inferior a 2 (dois) salários mínimos;

II - Desconto de 50\% (cinquenta por cento), no mínimo, no valor das passagens, para os idosos que excederem as vagas gratuitas, com renda igual ou inferior a 2 (dois) salários mínimos.

Adiante, os Art. 41 e 42, tratam das vagas reservadas em estacionamentos e segurança em transportes coletivos:

Art. 41 - É assegurada a reserva, para os idosos, nos termos da lei local, de 5\% (cinco por cento) das vagas nos estacionamentos públicos e privados, as quais deverão ser posicionadas de forma a garantir a melhor comodidade ao idoso.

Art. 42. São asseguradas a prioridade e a segurança do idoso nos procedimentos de embarque e desembarque nos veículos do sistema de transporte coletivo.

Não obstante, com o Estatuto do Idoso ainda não suprindo as necessidades da população idosa, (visto que, ao contrário do esperado, as diretivas não estavam sendo postas em prática), surge a demanda de uma readequação política: a Política Nacional de Saúde da Pessoa Idosa - PNSPI, que para tanto é sucedida.

O Estatuto do Idoso amplia a resposta do Estado e da sociedade às necessidades da população idosa, mas não traz consigo meios para financiar as ações propostas (...) assim, embora a legislação brasileira relativa aos cuidados da população idosa seja bastante avançada, a prática ainda é insatisfatória. A vigência do Estatuto do Idoso e seu uso como instrumento para a conquista de direitos dos idosos, a ampliação da Estratégia Saúde da Família que revela a presença de idosos e famílias frágeis e em situação de grande vulnerabilidade social e a inserção ainda incipiente das Redes Estaduais de Assistência à Saúde do Idoso tornaram imperiosa a readequação da Política Nacional de Saúde da Pessoa Idosa (PNSPI)" (Brasil, 2006, p.3).

A Política Nacional de Saúde da Pessoa Idosa - PNSPI, aprovada pela Portaria No 2.528, em 19 de outubro de 2006, considerando, dentre tantos outros pontos, a escassez de recursos socioeducativos e de saúde direcionados ao atendimento ao idoso, tem por finalidade primordial recuperar, manter e promover a autonomia e a independência dos indivíduos idosos, direcionando medidas coletivas e individuais de saúde para esse fim, em consonância com os princípios e diretrizes do Sistema Único de Saúde - SUS. É alvo dessa política todo cidadão e cidadã brasileiros com 60 anos ou mais de idade.

Junto às leis já citadas, há que mencionar o recente Decreto $\mathrm{N}^{\circ}$ 9.921, de 18 de julho de 2019, da Câmara dos Deputados, que consolida atos normativos editados pelo Poder Executivo Federal que dispõem sobre a temática da pessoa idosa. Tal decreto reafirma a necessidade de zelar pela prática dos direitos dos idosos, pelo levantamento de estudos sobre a situação da pessoa idosa no país, pela viabilização do atendimento preferencial aos idosos e acessibilidade aos meios de transporte. Eis os recortes dos artigos $4^{\circ}, 5^{\circ}, 18^{\circ}$ e $34^{\circ}$ :

Art. $4^{\circ}$, inciso VI - coordenar, financiar e apoiar estudos, levantamentos, pesquisas e publicações sobre a situação da pessoa idosa, de forma direta ou em parceria com outros órgãos ou entidades da administração pública; Inciso VIII zelar, em conjunto com o Conselho Nacional dos Direitos da Pessoa Idosa, pela aplicação das normas que dispõem sobre a proteção da pessoa idosa.

Art. $5^{\circ}$, inciso III - estabelecer critérios para viabilizar o atendimento preferencial à pessoa idosa.

Art. 18. A pessoa idosa terá atendimento preferencial nos órgãos e nas entidades da administração pública e nas instituições privadas prestadores de serviços à população. 
Art. 34. Dispõe sobre o acesso preferencial ao transporte coletivo pela pessoa idosa, no sistema de transporte coletivo interestadual nos modais rodoviário, ferroviário e aquaviário.

Existem, portanto, diversas Leis que asseguram os direitos dos idosos e consideram seu desrespeito ou infração como crimes ou violência praticados contra a pessoa idosa. Contudo, segundo Cardoso; Areosa (2016), existe uma distância entre o estabelecido na legislação brasileira e a realidade da população idosa quanto à atenção social e o nível de saúde.

Andrade et al (2013), ao discorrerem sobre a saúde da população idosa nos países em desenvolvimento, apontam que os aspectos que causam desigualdades, tornando o idoso um alvo vulnerável dentro do contexto social, são os que mais interferem na promoção de sua independência funcional, bem-estar e qualidade de vida. Ressalta dentre alguns fatos, "a dificuldade ao acesso à cultura e à educação, aos serviços de saúde e a falta de respeito nos transportes” (p.2). A autora sinaliza a necessidade de exigir do governo e sociedade formas de materializar as leis de garantia de proteção e efetivação dos direitos da pessoa idosa.

Santos (2013) ao estudar a situação social do idoso no espaço urbano atualmente, alega que em suas condições, estes se queixam “em filas de banco, do INSS, de hospitais ou outras instituições públicas (ou privadas)" (p.267) e reivindicam seu direito pelo assento e gratuidade nos ônibus. Percebe-se assim o constrangimento por qual passam para poder usufruir de seu direito garantido pela Lei.

Em contraponto, em relação às questões do âmbito social postas no questionário utilizado para o presente estudo, tais como o atendimento prioritário em repartições públicas e privadas, às vagas de estacionamento e gratuidade em passagens de ônibus, aproximadamente $90 \%$ da amostra se posicionou favoravelmente. Desse modo, apesar da maior parte dos participantes responderem que concordam com os direitos acima mencionados, o que se percebe é que não é exatamente isto o que ocorre em prática cotidiana, de acordo com as pesquisas de outrora e também as mais atualizadas mencionadas neste estudo.

Ainda no que concerne às questões do contexto social, 96,7\% da amostra afirmou ceder seu espaço para um idoso em um ônibus lotado. Ademais, resultado divergente é encontrado em estudo de Martins e Massarollo (2010), envolvendo uma entrevista com 63 idosos, trazendo resultados também discordantes com os dados obtidos em relação à prática do respeito e cumprimento aos direitos dos idosos dentro de serviços públicos, como o transporte coletivo:

\begin{abstract}
Algumas das grandes queixas das pessoas idosas estão relacionadas aos meios de transporte público, sendo que, o privilégio da "gratuidade do passe", que é assegurado por lei, muitas vezes se transforma em humilhação e discriminação, ferindo a condição de cidadão do idoso (...) foi reiterada, pelos participantes, a questão do desrespeito nos meios de transporte, sendo acrescentado que, ao entrar nos veículos, muitos motoristas não esperam o idoso se acomodar para dar a partida, causando desequilíbrio, quedas e traumas. Alguns idosos referiram que, quanto aos usuários jovens que se sentam nos bancos preferenciais, fingem que estão dormindo e não cedem o lugar aos idosos, fazendo com que o idoso viaje em pé. O desrespeito, segundo os entrevistados, faz com que alguns cobradores solicitem aos usuários mais jovens que cedam o lugar aos idosos e, mesmo assim, não são atendidos (Martins \& Massarollo, 2010. p.4).
\end{abstract}

Um segundo estudo acerca do idoso na contemporaneidade, publicado por Whitaker (2010), chama a atenção para as dificuldades vivenciadas pelo idoso, sua invisibilidade social como fruto da modernização e luta por seus direitos. Exemplificando a questão da hostilidade do espaço urbano, alertando para o transporte público, nos quais os idosos têm dificuldades para subir, além da falta de paciência dos motoristas e passageiros para com este público (já que são mais lentos que os demais), e que muitas vezes não aguardam o tempo que o idoso necessita para subir, ainda dirigindo.

A autora traz todos os participantes do contexto para a situação do evidente desrespeito ao direito do idoso, como os próprios motoristas de ônibus e demais passageiros, revelando que os sujeitos em nossa sociedade, como um todo, tendem a não cumprir com as leis que asseguram os direitos do público em questão. 
No que se refere à conduta tomada por parte das empresas de transporte, Penzin (2007) declara que embora existam leis e procedimentos estabelecidos para que o idoso possa usufruir dos seus direitos, em relação ao transporte público gratuito, este muitas vezes acaba não acontecendo; isto porque algumas empresas não cumprem o determinado, impedindo assim o uso de seus direitos. $\mathrm{O}$ autor destaca, então, a questão da necessidade de melhorias na fiscalização destas empresas, por parte do Estado, para que se evitem quaisquer formas de violação ou abuso com as pessoas idosas.

Nota-se então que o desrespeito em relação aos idosos acontece, com frequência, nos meios de transporte públicos, havendo muitas queixas sobre o comportamento de condutores e usuários jovens. Deste modo, se faz então por necessário compreender como se dá a relação entre os adultos jovens e as pessoas idosas, uma vez que o foco deste estudo é identificar a percepção e aceitação de adultos jovens sobre o processo de envelhecimento, bem como o conhecimento e posicionamento da amostra em relação aos direitos da pessoa idosa.

Neste sentido, no tocante às condições de tratamento dos mais jovens para com os mais velhos, em estudo conduzido com idosos, foram encontrados relatos das próprias pessoas idosas a quem entrevistaram Veras et al (2015). As autoras da pesquisa mencionam que pode haver questões preocupantes quanto às necessidades (psicológicas, enfatiza-se) do idoso e conflitos de convivência (familiares e sociais), uma vez que trazem relatos de pessoas idosas que chamam atenção para a questão da solidão e abandono, como os apresentados a seguir:

“[...] Aí o filho abandona a gente, vão cada um para suas casas, a gente fica muito isolada, aí vem mais doenças, complica mais, porque os filhos não dão mais bola pra gente, não escuta mais a gente, a gente depende muito deles" (D3).

“[...] Meu pai morreu, minha mãe morreu, meus irmãos são casados, [...] agora eu estou só com a sobrinha minha" (D8). (Veras et al, 2015, p.7).

Em seu estudo sobre solidão, depressão e qualidade de vida em idosos, Teixeira (2010) constata que esta fase do ciclo vital pode ser acompanhada de alguns acontecimentos marcantes, tais como as perdas de entes queridos, da atividade laboral e o afastamento dos familiares, com a saída dos filhos do lar - diminuindo então as redes sociais de contato - e que, usualmente, "com o passar da idade as relações sociais e a troca de apoio social diminuem" (p.3). Essas perdas acarretam sentimentos de desânimo e solidão às pessoas idosas, repercutindo em sua autoestima e qualidade de vida.

Dessa forma, percebe-se o quanto os idosos são excluídos da sociedade atual, contrariando os direitos postos pelo Estatuto do Idoso, a PNI (Política Nacional do Idoso) e a PNSPI (Política Nacional de Saúde da Pessoa Idosa). Destarte, considerando os estudos mencionados e publicados na literatura quanto ao tema e relacionando-os aos resultados desta pesquisa, cabe ser abordada aqui a questão da relevância da desejabilidade social, bem como exemplificar de que maneira esta pode ter influenciado nos dados dos respondentes envolvidos.

A respeito da desejabilidade social, Almiro (2017) destaca que esta se manifesta como a tendência dos sujeitos a responderem de acordo com o que for considerado pelas normas morais e cultura vigente como correto. Caracterizando aparentemente a necessidade da aprovação do meio social, os indivíduos usam de comportamentos que sejam condizentes com estas normas, ou seja, não respondem necessariamente pelo que lhes é próprio ou diz respeito, mas pelo que é coletivamente desejável.

Vieira e Lima (2015) ao realizarem em Sergipe um estudo com 393 adultos jovens a respeito dos estereótipos sobre os idosos e a dissociação entre crenças pessoais e coletivas, descobriram que houve uma dicotomia entre as crenças pessoais (que se apresentaram majoritariamente positivas) e as crenças coletivas (majoritariamente negativas). Isto é, quando se questionava aos participantes sua visão sobre a pessoa idosa, estes respondiam com aspectos positivos, ao passo em que quando se questionava, ainda aos mesmos participantes, acerca de como socialmente o idoso é visto, as respostas faziam emergir o conteúdo negativo. 
Neste sentido, os autores atribuem essa dicotomia à desejabilidade social e remetem à questão das mudanças dos últimos anos no âmbito social, com a luta e protestos por um tratamento igualitário para os grupos de minorias, de que fala Techio (2011) apud Vieira e Lima (2015), que geram pressões sociais, podendo causar o aparecimento desses conteúdos positivos aos quais nos referimos.

Por conta de seus efeitos e de sua indesejabilidade social, os estereótipos negativos normalmente são evitados em expressões abertas. Por isso, podem camuflar-se ou abrir espaço para conteúdos socialmente aceitáveis quando os indivíduos são convidados a falar sobre determinados temas (...) isso não significa, entretanto, que visões depreciativas deixaram de existir. Por vezes, esses conteúdos positivos manifestos dizem respeito a atributos menos valorizados socialmente, mantendo um status de desvalorização para grupos como o dos idosos. A necessidade de tratamento igualitário também pode criar uma tensão ao se exteriorizar concepções sobre os grupos, gerando uma organização particular nas declarações dos indivíduos sobre suas realidades (Vieira \& Lima, 2015, p. 950).

Outro aspecto a ser considerado na presente pesquisa se trata da composição da amostra, a qual se constituiu predominantemente por mulheres com nível superior de escolaridade. De fato, o gênero pode ser uma variável decisiva de interferência nesta pesquisa, e as mulheres realmente se apresentem como indivíduos que tomam posição mais favorável quanto aos direitos dos idosos. Além de que são pessoas com nível de escolaridade superior, condição que pode incidir numa melhor compreensão acerca do processo de envelhecimento (devido à circunstância de serem mais esclarecidas), entendendo esta fase do ciclo vital como algo mais natural e a pessoa idosa por uma ótica não pejorativa; e este seria um caso para se explorar em um estudo científico adiante.

\section{Conclusão}

Os resultados da pesquisa constataram que o envelhecimento é considerado uma etapa positiva da vida pela maioria dos participantes e que estes não sentem receio por envelhecer, além de afirmarem estar cientes e de acordo com as Políticas Públicas voltadas para os idosos, bem como os direitos desse público em sociedade. Assim, os dados obtidos diferem das pesquisas publicadas na literatura; no entanto, devem-se levar em consideração as contingências em sua totalidade e suas possíveis interferências neste estudo, a exemplo do fato de grande parcela da amostra ser constituída por mulheres com nível superior de escolaridade, atingindo assim um grupo discutível.

Além disso, há que se levar em consideração a relevância da desejabilidade social e suas implicações para estudos como este, quando a tendência a seguir certo caminho ou agir de determinada maneira (apresentando uma imagem mais favorável de si) precede o fato de aceitar e expor o que realmente se pensa.

Partindo desta premissa e do que foi discutido, deve-se reforçar a elaboração de mais pesquisas sobre o tema que considerem maior número de participantes e aspectos mais específicos a respeito do envelhecimento, a exemplo de estudos que enfatizem o olhar de profissionais da saúde e cuidadores/familiares de pessoas idosas; possíveis distinções entre as concepções de envelhecimento para o público masculino e feminino, dentre outros, a fim de investigar as particularidades de cada subgrupo. Ademais, ressalta-se a importância do papel do Estado para uma atitude rigorosa frente à fiscalização das práticas sociais quanto aos direitos dos idosos, para que o exercício de sua cidadania seja realmente assegurado. O planejamento em outras estratégias de Políticas Públicas para reforço desse cumprimento também é importante.

Sendo assim, a Psicologia enquanto ciência pode e deve contribuir para tais exercícios, abordando a temática das peculiaridades da pessoa idosa e dessa fase do ciclo de vida, sobretudo dentro dos próprios Conselhos - Municipal, Estadual e Nacional - do idoso, este profissional pode estar presente, promovendo o acesso aos direitos. O psicólogo, lançando mão de seu arcabouço de conhecimentos, pode atuar na promoção de discussões com os mais jovens que favoreçam a desmistificação dos aspectos negativos do envelhecimento, enquanto que com os próprios idosos, este profissional poderá tratar de questões 
como, por exemplo, a autoaceitação e autoestima, o medo de envelhecer e o medo da morte, qualidade de vida e outros aspectos.

\section{Referências}

Almiro, P. A. (2017). Uma nota sobre a desejabilidade social e o enviesamento de respostas. Aval Psicol 16(3).

Andrade, L. M., Sena E. L. D. S., Pinheiro, G. M. L., Meira, E. C., \& Lira, L. S. S. P. (2013). Políticas públicas para pessoas idosas no Brasil: uma revisão integrativa. Ciência \& Saúde Coletiva. 18: 3543-3552.

Boaventura, V. C. Representações Sociais da Velhice: estudo realizado junto aos jovens do ensino médio do Colégio Estadual Edvaldo Brandão Correia e do Colégio Simonton, Cachoeira - BA. Monografia (Graduação em Serviço Social) - Centro de artes, humanidades e letras - CAHL, Universidade Federal do Recôncavo da Bahia, Cachoeira; 2012.

Brasil, Lei n 10.741/2003. Dispõe sobre o Estatuto do Idoso e dá outras providências. Brasília: Senado Federal, https://www2.senado.leg.br/bdsf/bitstream/handle/id/530232/estatuto_do_idoso_1ed.pdf.

Brasil, Ministério da Saúde. Portaria n 2.528, de 19 de outubro de 2006. Aprova a política nacional de saúde da pessoa idosa. Brasília, DF, 19 out. 2006; http://bvsms.saude.gov.br/bvs/saudelegis/gm/2006/prt2528_19_10_2006.html.

Brasil, Lei $\mathrm{n}^{\mathrm{o}}$ 8.842, de 4 de janeiro de 1994. Dispõe sobre a política nacional do idoso, cria o Conselho Nacional do Idoso e dá outras providências. Presidência da República - Casa civil - subchefia para assuntos jurídicos, Brasília, DF, 4 jan. 1994; http://www.planalto.gov.br/ccivil_03/leis/18842.htm.

Caldas C. P., \& Thomaz A. F. A velhice no olhar do outro: uma perspectiva do jovem sobre o que é ser velho 2010. Revista Kairós: Gerontologia; 13(2): 7589.

Ciosak, S. I., Braz, E., Costa, M. F. B. N. A., Nakano, N. G. R., Rodrigues, J., Alencar, R. A., \& Rocha, A. C. A. Senescência e senilidade: novo paradigma na atenção básica de saúde. Revista da Escola de Enfermagem da USP (2011), 45: 1763-1768.

Câmara dos deputados, Decreto No 9.921, de julho de 2019. Diário Oficial da União - Seção 1. Palácio do Congresso Nacional - Praça dos Três Poderes Brasília - DF - Brasil; 2019 https://www2.camara.leg.br/legin/fed/decret/2019/decreto-9921-18-julho-2019-788848-publicacaooriginal-158755-pe.html.

Cajueiro, R. L. P. (2013). Manual para elaboração de trabalhos acadêmicos: guia prático do estudante. (3a ed.), Saraiva

Guterres, C. C., \& Virginia, C. A. S. (2016). A política nacional de saúde da pessoa idosa (PNSPI): a visão dos gestores em Santa Cruz Do Sul e região. Jornada de Pesquisa em Psicologia; 2016.

Cruz, R. C. D., \& Ferreira, M. D. A. (2011); Um certo jeito de ser velho: representações sociais da velhice por familiares de idosos. Texto \& ContextoEnfermagem. 20(1): 144-151.

Del-Masso, M. C. S. (2015). Universidade aberta à terceira idade: percurso de uma história na UNESP. Envelhecimento humano: diferentes olhares. Marília: Cultura Acadêmica: $19-39$.

Horn, V. Q. A imagem da velhice na contemporaneidade. Santa Rosa, 2013. Monografia (Graduação em Psicologia) - Universidade Regional do Noroeste do Estado do Rio Grande do Sul- Unijuí, 2013.

IBGE - Instituto Brasileiro de Geografia e Estatística. Projeções da População. Edição 2018.

IHU - Instituto Humanitas Unisinos (Revista Online) O envelhecimento populacional segundo as novas projeções do IBGE. Setembro de 2018. http://www.ihu.unisinos.br/78-noticias/582356-o-envelhecimento-populacional-segundo-as-novas-projecoes-do-ibge.

Marconi, M. A. \& Lakatos, E. M. (2018). Fundamentos de Metodologia Científica. Atlas.

Marin, M. J. S., \& Panes, V. C. B. (2015). O envelhecimento e a questão da qualidade de vida. In: DÁTILO, Gilsenir Maria Prevelato de Almeida; Cordeiro AP (Orgs.) Envelhecimento Humano: diferentes olhares. Cultura Acadêmica; 221- 237.

Martins, M. S., \& Massarollo, M. C. K. B. (2010). Conhecimento de idosos sobre seus direitos. Acta Paul Enferm. 4: $479-485$.

Moresi E. Metodologia da Pesquisa. Brasília, 2003. Monografia (Pós-Graduação stricto sensu em gestão do conhecimento e tecnologia da informação) Universidade Católica de Brasília, 2003.

Miranda, G. M. D., Mendes, A. D. C. G., \& Silva, A. L. A. D. O envelhecimento populacional brasileiro: desafios e consequências sociais atuais e futuras. Revista brasileira de geriatria e gerontologia; 2016; 19: 507-519.

Paz, S. F., de Melo, C. A., \& da Motta Soriano, F. A violência e a violação de direitos da pessoa idosa em diferentes níveis: individual, institucional e estatal. O social em questão; 2012; (28): 57-83.

Penzin, F. L. (2007). Direito dos Idosos: A Gratuidade nos Transportes Coletivos Urbanos. Monografria (Graduação em Direito) - Pontifícia Universidade Católica do Rio de Janeiro, 2007.

dos Pinheiro, O. D., \& Areosa, S. V. C. (2019). A importância de políticas públicas para idosos. Revista Baru-Revista Brasileira de Assuntos Regionais e Urbanos; 4(2): 183-193. 
Research, Society and Development, v. 10, n. 17, e68101724176, 2021

(CC BY 4.0) | ISSN 2525-3409 | DOI: http://dx.doi.org/10.33448/rsd-v10i17.24176

Rosa, C. S. (2014). A velhice na cultura ocidental: considerações sobre a experiência contemporânea de envelhecer. Ijuí, Monografia (Graduação em Psicologia) - Universidade Regional do Rio Grande do Sul, 2014.

Santos, J. S. D. (2013). Atendimento preferencial no Estatuto e na voz do idoso: uma análise discursiva. Linguagem em (Dis) curso; 13 : $243-271$.

Schneider, R. H., \& Irigaray, T. Q. (2008). O envelhecimento na atualidade: aspectos cronológicos, biológicos, psicológicos e sociais. Estudos de Psicologia (Campinas); 2008; 25: 585-593.

Takeuti, N. M. Paradoxos societais e juventude contemporânea. Estudos de Psicologia (Natal); 2012; 17: 427-434.

Teixeira, L. M. F. (2010). Solidão, depressão e qualidade de vida em idosos: um estudo avaliativo exploratório e implementação-piloto de um programa de intervenção. Monografia (Mestrado em Psicologia) - Universidade de Lisboa, 2010.

Torres, T. D. L., Camargo, B. V., Boulsfield, A. B., \& Silva, A. O. (2015). Representações sociais e crenças normativas sobre envelhecimento. Ciência \& Saúde Coletiva; 20: 3621-3630.

Veras, M. L. M., Teixeira, R. S., Granja, F. B. C., \& Batista, M. D. R. F. F. (2015). Processo de envelhecimento: um olhar do idoso. Revista interdisciplinar; 8(2): 113-122.

Veras, R. P., \& Oliveira, M. (2018). Envelhecer no Brasil: a construção de um modelo de cuidado. Ciência \& saúde coletiva; 23(6): $1929-1936$.

Vieira, R. D. S., \& Lima, M. E. O. (2015). Estereótipos sobre os idosos: dissociação entre crenças pessoais e coletivas. Temas em Psicologia; 23(4): 947-958.

Whitaker, D. C. A. (2010). O idoso na contemporaneidade: a necessidade de se educar a sociedade para as exigências desse" novo" ator social, titular de direitos. Cadernos Cedes; 30(81):179-188. 